\title{
Thermophysical properties of the products of low-grade fuels thermal recycling
}

\author{
Roman B. Tabakaeva, Alexander V. Astafev, Alexander V. Kazakov, and Alexander S. Zavorin \\ National Research Tomsk Polytechnic University, 634050 Tomsk, Russia
}

\begin{abstract}
The relevance of the work is caused by reorientation of the modern power engineering to use of local low grade fuel resources. Some types of low grade fuels (peat, brown coal, sapropel, wood chips) are considered in this work. Thermotechnical characteristics of the investigated fuels and products of their thermal recycling are determined. Thermal recycling process is accompanied by release of fuel dissociation heat $(0.33-3.69 \mathrm{MJ} / \mathrm{kg})$. The results of thermal low grade fuel recycling are solid carbonaceous product (semi-coke) with a calorific value higher in 1.5-7 times than the value of natural fuels; pyrolysis resin with calorific value 29.4-36.8 MJ/kg; combustible gas with calorific value $15.16-19.06 \mathrm{MJ} / \mathrm{m} 3$.
\end{abstract}

\section{Introduction}

The gradual exhaustion of qualitative energy resources, such as natural gas and coal, and the reorientation of their use in the area of chemical industry, lead to the necessity of a new direction in energy development.

The reorientation of power engineering to use of non-traditional renewable energy resources has already observed: national programs to increasing of renewable resources share in fuel energy balance have adopted in more than 73 countries [1].

"The Energy Development Strategy of Russia until 2030", adopted by the Russian government as an evolution model in power engineering, envisages a gradual reduction of a natural gas share for energy use and the power replenishment by entering of the units, working on renewable resources. The particular attention is paid to low grade fuel: the resources of peat, biomass, low quality brown coal and sapropel. At the same time, use of these fuels is particularly useful in decentralized energy supply areas, power engineering of which is based on the autonomous power units, worked on imported raw materials (coal or diesel fuel). Most of these materials are supplied by commercial structures after the resale, this fact together with the annual transportation tariffs increase lead to expansion of value by more than twice.

The thermotechnical characteristics (high moisture and ash content, low calorific value), fragility, small fractional composition, consolidation, sticking and congealing during transportation of low grade fuel hinder his wide dissemination as an energy resource. Therefore, the use of low grade fuels in existing boiler equipment by traditional combustion technologies is inefficiently and almost nonexistent.

${ }^{a}$ Corresponding author: TabakaevRB@tpu.ru 
Accordingly, the providing of method by effective low grade fuel involvement to the power engineering is the actual problem of scientific research.

The thermal recycling is one of possible ways to effective energy use of these fuels [2-9]. However, in order to the evaluation of feasibility and the choice of final recycling product is necessary to know thermophysical properties of the resulting products.

\section{The methodology and results of experiments}

Low grade fuels of the Tomsk region - peat from deposits Sukhovskoe, Arkadevskoe and Kandinskoe, brown coal from Talovskoe deposit, lake sapropel from deposit Karasevoe and wood chips of different wood species are investigated (Table 1).

Table 1. The thermotechnical characteristics of the some low grade fuel types in Tomsk region

\begin{tabular}{|l|c|c|c|c|c|c|}
\hline \multirow{2}{*}{ Thermotechnical characteristic } & \multicolumn{3}{|c|}{ Peat } & \multirow{2}{*}{ Coal } & \multirow{2}{*}{ Sapropel } & \multirow{2}{*}{ Wood chips } \\
\cline { 2 - 7 } & Sukhovskoy & Arkadevsky & Kandinsky & & & \\
\hline Moisture $W_{t}^{r}, \%$ & 59.6 & 38.2 & 72.8 & 51.0 & 67.0 & 45.0 \\
\hline Ash content $A^{d}, \%$ & 39.5 & 31.5 & 9.1 & 25.9 & 38.4 & 0.6 \\
\hline Volatile yield $V^{d a f}, \%$ & 69.3 & 71.0 & 71.6 & 63.2 & 84.8 & 91.8 \\
\hline Lower calorific value $Q_{i}^{r}, \mathrm{MJ} / \mathrm{kg}$ & 4.2 & 7.3 & 3.1 & 8.6 & 2.1 & 9.3 \\
\hline
\end{tabular}

To implementation of the thermal recycling of these fuels by pyrolysis is designed laboratory unit (Figure 1), for work of which the fuel is fed into the reactor 1, and then it is hermetically closed and placed into the heating element 2 . The heating power is set by means of the autotransformer 3 , guided by the ammeter 4 and voltmeter 5 . The temperature recorder 6 and system of thermocouples 7 are provided for temperature process fixing.

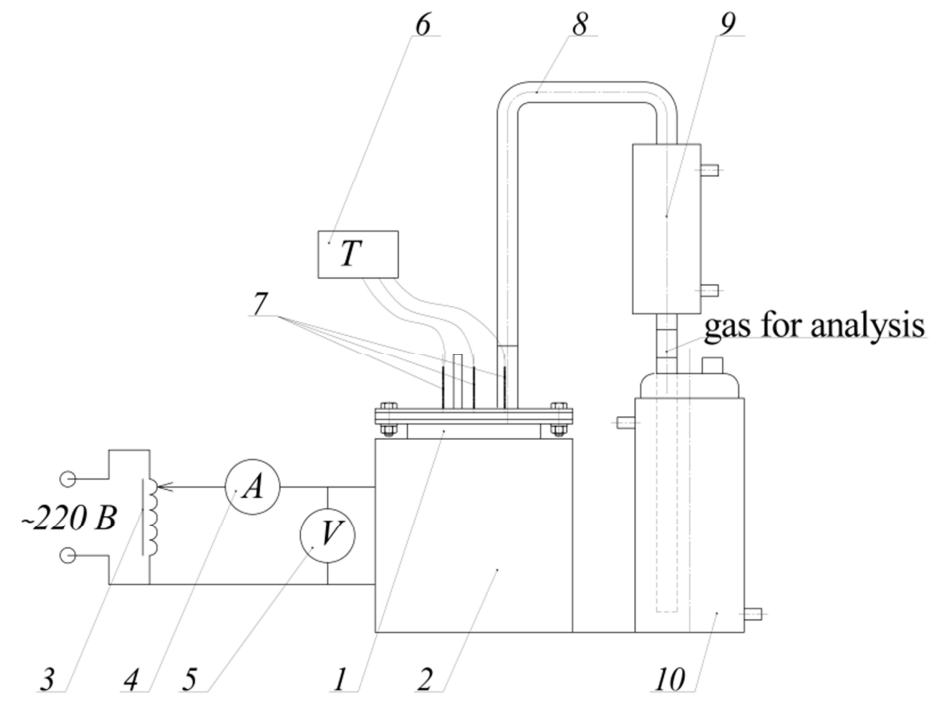

Figure 1. Experimental unit of thermal recycling: 1 - reactor, 2 - heating element, 3 - autotransformer, 4 - ammeter, 5 - voltmeter, 6 - temperature recorder, 7 - thermocouples, 8 - hose, 9 - refrigerator, 10 - condenser.

The volatile pyrolysis products (pairs of pyrogenetic moisture and resin, gas) release from organic raw materials during heating, leave the reactor 1 and go to the cooled tank 10 through the heat resistant hose 8 and refrigerator 9. Upon cooling, the pairs of pyrogenetic moisture and resin are condensed and collected in the tank 10. The gas samples for analysis were taken in the connection of the refrigerator 9 and the cooled tank 10. After the process semi-coke is extracted from reactor, which 
cooled by air, the condensate from tank 10 is sifted through filter paper for separating to pyrogenetic moisture and resin. The resulting products are weighed, and the mass of the resulting gas is determined as the difference between the raw material mass and the mass of other products (semicoke, pyrogenetic moisture and resin).

The material balance and characteristics of the products, which obtained by thermal recycling at $450{ }^{\circ} \mathrm{C}$, are shown in Tables $2-5$.

Table 2. The material balance (comparatively of the raw material dry mass)

\begin{tabular}{|l|c|c|c|c|c|c|}
\hline \multirow{2}{*}{ Recycling product } & \multicolumn{7}{|c|}{ Product yield, \% } \\
\cline { 2 - 7 } & $\begin{array}{c}\text { Sukhovskoy } \\
\text { peat }\end{array}$ & $\begin{array}{c}\text { Arkadevsky } \\
\text { peat }\end{array}$ & $\begin{array}{c}\text { Kandinsky } \\
\text { peat }\end{array}$ & Coal & Sapropel & $\begin{array}{c}\text { Wood } \\
\text { chips }\end{array}$ \\
\hline Semi-coke & 60.7 & 74.8 & 43.4 & 58.8 & 67.4 & 31.1 \\
\hline $\begin{array}{l}\text { Pyrolysis condensate, } \\
\text { including: }\end{array}$ & 20.3 & 12.0 & 26.2 & 19.0 & 14.1 & 23.6 \\
\hline $\begin{array}{l}\text { - resin } \\
\text { Combustible gas }\end{array}$ & 3.9 & 4.8 & 6.3 & 8.2 & 4.6 & traces \\
\hline
\end{tabular}

Table 3. The thermotechnical characteristics of semi-coke

\begin{tabular}{|l|c|c|c|c|c|c|}
\hline \multirow{2}{*}{ thermotechnical characteristic } & \multicolumn{3}{|c|}{ Peat } & \multirow{2}{*}{ Coal } & \multirow{2}{*}{ Sapropel } & \multirow{2}{*}{ Wood chips } \\
\cline { 2 - 7 } & Sukhovskoy & Arkadevsky & Kandinsky & & & \\
\hline Moisture $W_{t}^{r}, \%$ & $\sim 0.0$ & $\sim 0.0$ & $\sim 0.0$ & $\sim 0.0$ & $\sim 0.0$ & $\sim 0.0$ \\
\hline Ash content $A^{d}, \%$ & 48.8 & 61.9 & 22.9 & 38.5 & 56.5 & 3.5 \\
\hline Volatile yield $V^{\text {daf }}, \%$ & 25.1 & 18.6 & 23.3 & 12.7 & 19.8 & 15.7 \\
\hline Lower calorific value $Q_{i}^{r}, \mathrm{MJ} / \mathrm{kg}$ & 14.4 & 11.1 & 21.5 & 18.2 & 10.0 & 31.9 \\
\hline
\end{tabular}

Table 4. The thermotechnical characteristics of pyrolysis resin

\begin{tabular}{|l|c|c|c|c|c|}
\hline \multirow{2}{*}{ thermotechnical characteristic } & \multicolumn{3}{|c|}{ Peat } & \multirow{2}{*}{ Coal } & \multirow{2}{*}{ Sapropel } \\
\cline { 2 - 5 } & Sukhovskoy & Arkadevsky & Kandinsky & & \\
\hline Moisture $W_{t}^{r}, \%$ & $\sim 0.0$ & $\sim 0.0$ & $\sim 0.0$ & $\sim 0.0$ & $\sim 0.0$ \\
\hline Ash content to dry mass $A^{d}, \%$ & $\sim 0.0$ & $\sim 0.0$ & $\sim 0.0$ & $\sim 0.0$ & $\sim 0.0$ \\
\hline Volatile yield $V^{\text {daf }}, \%$ & 100.0 & 100.0 & 100.0 & 100.0 & 100.0 \\
\hline Lower calorific value $Q_{i}^{r}, \mathrm{MJ} / \mathrm{kg}$ & 34.2 & 29.5 & 29.4 & 33.1 & 36.8 \\
\hline
\end{tabular}

Note: the pyrolysis resin at the wood chips recycling is absent

Table 5. The average gas composition and his calorific value at a temperature diapason from 200 to $450{ }^{\circ} \mathrm{C}$

\begin{tabular}{|c|c|c|c|c|c|c|c|}
\hline \multirow{2}{*}{ Fuel } & \multicolumn{5}{|c|}{ Fuel gas composition, $\%$} & \multirow{2}{*}{$\begin{array}{c}\text { Gas calorific } \\
\text { value } Q_{d}^{i}, \mathrm{MJ} / \mathrm{m}^{3}\end{array}$} & \multirow{2}{*}{$\begin{array}{l}\text { Calorific value to } 1 \mathrm{~kg} \text { o } \\
\text { gas } Q_{d}^{i}(\operatorname{mass}), \mathrm{MJ} / \mathrm{kg}\end{array}$} \\
\hline & $\mathrm{H}_{2}$ & $\mathrm{CO}$ & $\mathrm{CH}_{4}$ & $\mathrm{C}_{\mathrm{m}} \mathrm{H}_{\mathrm{n}}$ & $\mathrm{CO}_{2}+\mathrm{N}_{2}$ & & \\
\hline Sukhovskoy peat & 25.88 & 9.36 & 10.81 & 11.79 & 42.16 & 16.24 & 14.12 \\
\hline Arkadevsky peat & 27.59 & 9.11 & 9.73 & 10.59 & 42.98 & 15.16 & 13.22 \\
\hline Kandinsky peat & 23.81 & 9.80 & 12.93 & 12.79 & 40.68 & 17.55 & 15.27 \\
\hline Coal & 15.90 & 11.68 & 16.02 & 11.18 & 45.22 & 16.90 & 13.38 \\
\hline Sapropel & 26.84 & 7.60 & 10.21 & 12.83 & 42.52 & 16.65 & 14.59 \\
\hline Wood chips & 6.46 & 25.99 & 19.26 & 11.48 & 36.81 & 19.06 & 14.73 \\
\hline
\end{tabular}

The material balance of thermal recycling shows that wood chips and kandinsky peat are can considered as a raw material for obtaining of semi-coke and gas. The lower calorific value of semicoke greater than calorific value of low grade natural fuels in 1.5-7 times. However, the ash content of semi-coke increases in 1.4-5.8 times (of calculation to dry mass). The pyrolysis resin has a high calorific value (29.4-36.8 MJ/kg), but the lowest yield of calculation to dry raw material mass. The combustible gas has a high calorific value (15.16-19.06 MJ/kg), despite of the large ballast share.

The results allow to evaluate how much of the heat is released during the process of dry raw material pyrolysis - the fuel dissociation heat (Figure 2). Was established that calorific value at the pyrolysis of investigated fuels has a positive meaning about 0.33-3.69 MJ/kg. Accordingly, variants are possible, at which heat from the obtained gas combustion together with the own fuel dissociation 
heat will be sufficient for autothermal of the pyrolysis process. The possibility of autothermal process of low temperature pyrolysis is shown in researches of A.V. Kazakov [10, 11], A.N. Subbotin и R.N. Kulesh [12].

a)

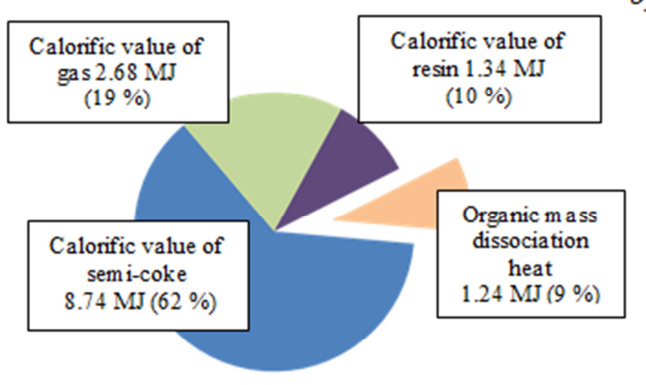

c)

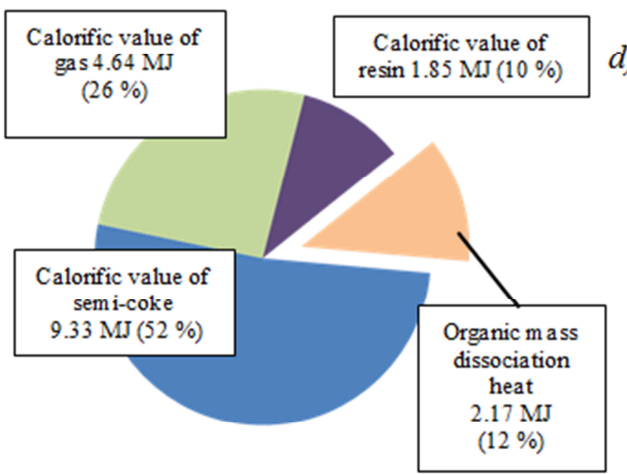

e)

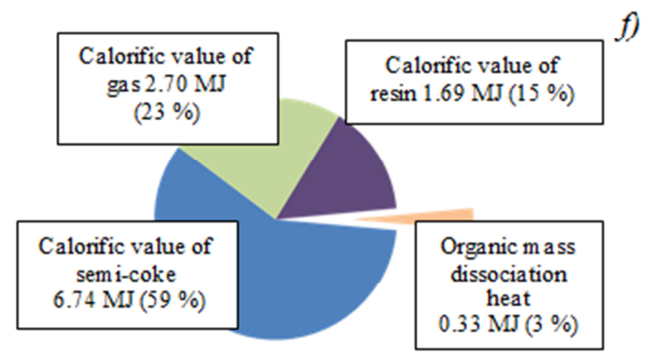

b)
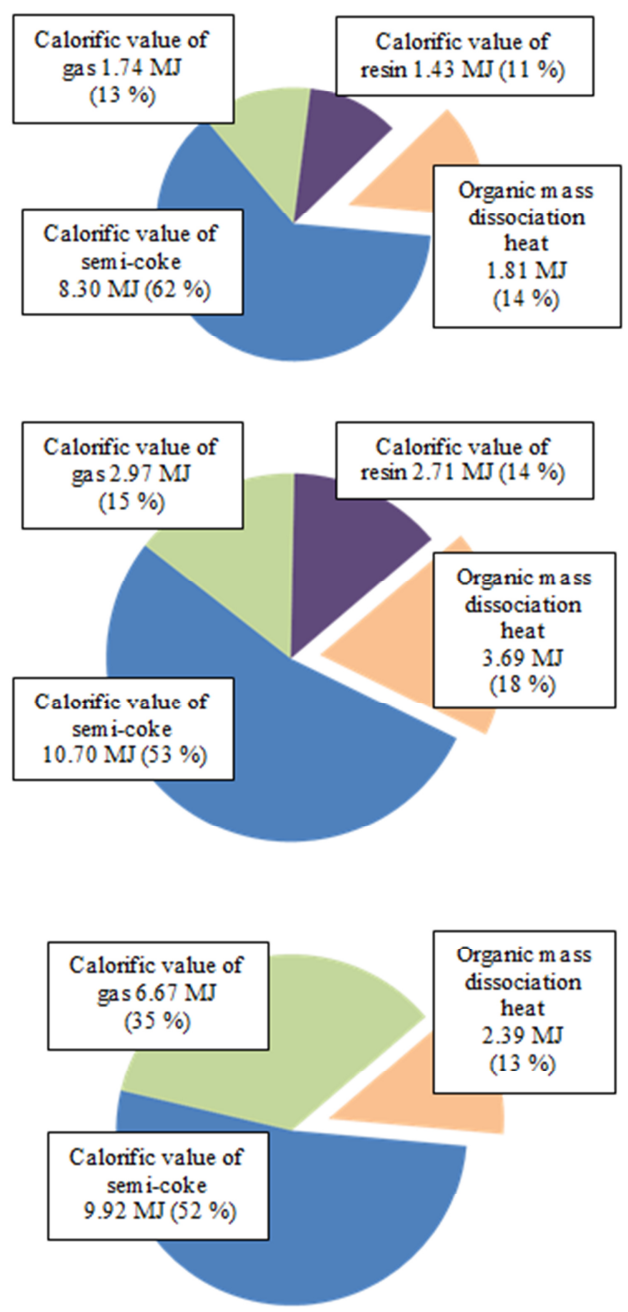

Figure 2. The distribution of the potential heat release between the pyrolysis products of the $1 \mathrm{~kg}$ of dried low grade raw material: a) - Sukhovskoy peat; b) - Arkadevsky peat; c) - Kandinsky peat; d) - Talovsky coal; e) - lake sapropel; f) - wood chips.

\section{Conclusion}

1. The thermal recycling of low grade fuels allows to obtain a solid carbonaceous product (semi-coke) with a calorific value higher in 1.5-7 times than the value of natural fuels.

2. The pyrolysis resin has the highest calorific value, but the lowest yield (at wood chips recycling equal zero).

3. The combustible gas has a high calorific value $\left(15.16-19.06 \mathrm{MJ} / \mathrm{m}^{3}\right)$.

4. The pyrolysis of investigated fuels proceeds with release of 0.33-3.69 MJ of heat to $1 \mathrm{~kg}$ of fuel.

The reported study was partially supported by the Ministry of education and science of The Russian Federation, state order No. 13.948.2014/K. 


\section{References}

1. O.S. Popel, B.F. Reutov, A.P. Antropov, Thermal engineering 11, 909 (2010).

2. N. Abas, A. Kalair, N. Khan, Futures 69, 31 (2015)

3. B.J. Ward, T.W. Yacob, L.D. Montoya, Environmental Science and Technology 48, 9852 (2014)

4. A.V. Kazakov, R.B. Tabakaev, P.Y. Novoseltsev, A.V. Astafev, MATEC Web of Conferences 19, 01014 (2014)

5. A.S. Zavorin, R.B. Tabakaev, P.Y. Novoseltsev, A.V. Astafev, MATEC Web of Conferences 19, 01015 (2014)

6. A.S. Zavorin, A.V. Kazakov, A.A. Makeev, S.V. Podorov, Thermal Engineering 57, 77 (2010)

7. P.S. Gergelizhiu, S.A. Khaustov, R.B. Tabakaev, P.U. Novoseltsev, A.V. Kazakov, A.S. Zavorin, in Proceedings of 2014 International Conference on Mechanical Engineering, Automation and Control Systems (MEACS 2014), 2014, 6986901

8. R.A. Visloguzov, R.B. Tabakaev, A.S. Zavorin, S.V. Dolgov, K.I. Klochko, in Proceedings of 2014 International Conference on Mechanical Engineering, Automation and Control Systems (MEACS 2014), 2014, 6986943

9. R.B. Tabakaev, P.S. Gergelizhiu, A.V. Kazakov, A.S. Zavorin, IOP Conference Series: Materials Science and Engineering 66, 012052 (2014).

10. A.V. Kazakov, T.M. Plakhova, R.I. Popov, MATEC Web of Conferences 19, 01019 (2014)

11. N.V. Suglobova, T.M. Plakhova, A.V. Kazakov, A.S. Zavorin, in 9th International Forum on Strategic Technology (IFOST 2014), 2014, 386

12. R.N. Kulesh, A.N. Subbotin, Bulletin of the Tomsk Polytechnic University 321, 15 (2012) [in Russian] 